\title{
Immunocytochemical Localization of Protein Kinase C Isozymes in Rat Brain
}

\author{
Freesia L. Huang, ${ }^{1}$ Yasuyoshi Yoshida, ' Hiroki Nakabayashi,' W. Scott Young, III,' ${ }^{2}$ and Kuo-Ping Huang' \\ 'Section on Metabolic Regulation, Endocrinology and Reproduction Research Branch, National Institute of Child Health \\ and Human Development, and 'Laboratory of Cell Biology, National Institute of Mental Health, National Institutes of \\ Health, Bethesda, Maryland 20892
}

Recently, we isolated 3 protein kinase C (PKC) isozymes from rat brain (Huang et al., 1986a). Using isozyme-specific antibodies for immunoblot, we have determined the relative levels of each isozyme in various regions of the rat brain (Huang et al., 1987b). The present paper describes the cellular distributions of PKC isozymes in rat brain as determined by light microscopic immunocytochemistry. Staining with PKC antibodies revealed strong immunoreactivities in neuronal somata and their dendrites and weak to no reaction in axon and the astroglial structures. In the cerebellum, the type I PKC antibodies stained the Purkinje cell bodies and dendrites; the type II PKC antibodies stained the granule cells; and the type III PKC antibody stained both Purkinje and granule cells. In the cerebral cortex, all antibodies stained neurons resembling pyramidal cells and their apical dendrites in layers II to VI, while layer I was nearly devoid of staining. However, the various isozyme-specific antibodies revealed distinct laminar distribution patterns of the positively stained neurons, and the type III PKC-positive neurons exhibited a higher density than those of type I or II PKC-positive ones, especially in layer II of cingulate (retrosplenial) and piriform cortices. In the hippocampal formation, both pyramidal cells of the hippocampus and granule cells of the dentate gyrus were stained by all PKC antibodies. Subcellularly, type III PKC appeared mostly in the cytoplasm of these neurons, whereas type I and II PKC seemed to associate with the nucleus as well. In the olfactory bulb, both type II and III PKC antibodies stained the periglomerular and granular cells, and the latter also stained the mitral cells. The distinct cellular and subcellular distribution of PKC isozymes suggests that each isozyme plays a unique role in the various neural functions.

Protein kinase $\mathrm{C}(\mathrm{PKC})$ is a calcium-dependent and phospholipid-activated protein kinase first described by Nishizuka and his coworkers (Inoue et al., 1977; for reviews, see Nishizuka, 1984, 1986). The enzyme is widely distributed in various tissues and is most concentrated in brain (Kuo et al., 1980). In vivo $\mathrm{PKC}$ is believed to be activated by diacylglycerol produced from the receptor-mediated hydrolysis of inositol phospholipid (Berridge and Irvine, 1984), and this activation seems to be involved

Received Jan. 21, 1988; revised Apr. 15, 1988; accepted Apr. 18, 1988.

Correspondence should be addressed to Dr. Freesia Huang, Building 10, Room 8C407, National Institutes of Health, Bethesda, MD 20892.

Copyright (C) 1988 Society for Neuroscience $0270-6474 / 88 / 124734-11 \$ 02,00 / 0$ in numerous fundamental cellular processes such as metabolism, secretion, growth, and differentiation (Nishizuka, 1984, 1986). PKC has also been identified as the cellular receptor of the tumor-promoting phorbol esters which elicit a spectrum of physiological responses (Nishizuka, 1984, 1986). In the central nervous system, PKC has been implicated in enhancing neurotransmitter release (Malenka et al., 1986, 1987), regulation of ion channels (Baraban et al., 1985; Madison et al., 1986), and modification of neuronal plasticity (Routtenberg et al., 1985; Akers et al., 1986). However, the roles of PKC in these diverse functions are unknown, and investigations are especially complicated by the discovery of 3 related yet distinct PKC genes from brain, designated $\alpha, \beta$, and $\gamma$ (Coussens et al., 1986; Knopf et al., 1986; Ono et al., 1986; Ohno et al., 1987), which have been localized on different human chromosomes (Coussens et al., 1986). Transcripts of these PKC genes in certain brain regions have been identified both by Northern blot analysis (Parker et al., 1986) and in situ hybridization histochemistry (Brandt et al., 1987).

Previously we isolated 3 isozymic forms of PKC, designated types I, II, and III, from rat brain by hydroxylapatite column fractionation (Huang et al., 1986a). These PKC isozymes all have $M_{r}$ of 82,000 , and all possess kinase and phorbol esterbinding activities dependent on calcium and phospholipid but have different sites of autophosphorylation. They also have different immunoreactivities toward 2 monoclonal antibodies and a preparation of polyclonal antibodies (Huang and Huang, 1986) raised against a mixture of rat brain PKC isozymes. The corresponding $\mathrm{PKC}$ isozymes were subsequently identified in rabbit (Jaken and Kiley, 1987) and monkey brains (Huang et al., 1987a). Recently, the type I, II, and III PKCs were identified as products of $\gamma, \beta$, and $\alpha$ PKC genes, respectively (Huang et al., 1987b). Using the isozyme-specific antibodies purified from the polyclonal antibodies, we quantified each PKC isozyme in various regions of brain (Huang et al., 1987a). The fact that these PKC isozymes were heterogeneously distributed among various brain regions prompted us to map the cellular localization of each PKC isozyme. The present communication describes our immunofluorescent staining of brain sections with isozyme-specific antibodies. In the cerebellum, each isozyme was associated with a distinctive layer of cells; in the cerebral cortex, all 3 types of PKC were present in neurons, albeit with somewhat different abundance and subcellular localizations. The present information at light microscopic level together with in vitro characterization of the isozymes should facilitate the elucidation of the involvement of PKC isozymes in a variety of neuronal functions. 


\section{Materials and Methods}

Materials. Affinity-purified biotin-conjugated goat anti-mouse IgG and rabbit anti-goat IgG and Texas Red-conjugated avidin were from Cooper Biochemical. Normal goat and rabbit sera and normal mouse IgG were from Miles. Crystallized bovine plasma albumin was from Armour Pharmaccutical company. PBS, pH 7.4, was from Gibco.

Preparation of isozyme-specific antibodies. Rat brain type I, II, and III PKCs were purified to near homogeneity by various column chromatographies, including hydroxylapatite as described (Huang et al, 1986a, 1987a). These purified PKC isozymes were used to prepare isozyme-specific antibodies from the polyclonal antibodies previously prepared in goat against a mixture of rat brain PKC isozymes by immunoabsorbtion according to the method of Olmsted (1981). While the unfractionated polyclonal antibodies recognized all 3 types of PKC, the purified antibodies preferentially reacted with a single type of PKC isozyme in immunoblot analysis as previously demonstrated (Huang et al., 1987a). These isozyme-specific antibodies were referred to as MSI, -II, and -III for monospecific antibodies against type I, II, and III PKCs, respectively, though they were polyclonal. Several monoclonal antibodies against PKC isozymes wcre obtaincd previously (Huang et al., 1986a). Ascites fluids of clones $1 / 4$ and $8 / 1$, which cross-reacted with type I and II PKC (Nakabayashi and Huang, 1988), respectively, were used in the present study and were referred to as MC-I and MCII.

Indirect immunofluorescent staining. Frozen brains of adult SpragueDawley rats previously perfused with cold $4 \%$ paraformaldehyde in 120 $\mathrm{mm}$ phosphate buffer, pH 7.4, were used. Serial brain sections (12 $\mu \mathrm{m}$ thick) at various levels were used for the staining. Sections were warmed to room temperature and thoroughly rehydrated with PBS before staining. Occasionally, before incubation with primary antibodies, brain sections were blocked with normal rabbit serum ( $2 \%$ in PBS) when monospecific polyclonal antibodies were to be used or blocked with normal goat serum when monoclonal antibodies were to be used. However, this blocking did not improve the staining significantly and was not $\mathrm{cm}$ ployed later in the study. Incubations with the primary antibodies, either monospecific or monoclonal, were at $4^{\circ} \mathrm{C}$ for $40 \mathrm{hr}$. The second antibodies used (1:250 dilution) were biotin-conjugated rabbit anti-goat IgG for monospecific antibodies and biotin-conjugated goat anti-mouse IgG for monoclonal antibodies, and the incubations were at room temperature for $1 \mathrm{hr}$. Finally, the sections were incubated with Texas Redconjugated avidin at a concentration of $7 \mu \mathrm{g} / \mathrm{ml}$ avidin (molar ratio of Texas Red/avidin $=3$ ) at room temperature for $1 \mathrm{hr}$. Bovine plasma albumin, $2 \mathrm{mg} / \mathrm{ml}$ in PBS, was used as diluent at all steps. Between incubations, sections were washed twice with PBS, each for at least 10 min. Four washes were done at the completion of the staining, and the sections were rinsed with deionized water, air-dried, and mounted with buffered polyvinylalcohol for fluorescent microscopy and photography. During the initial trial staining, brain sections were hydrated with PBS containing $0.1 \%$ Nonidet $P 40$, and the same detergent was also included in the solution of primary antibody for staining. However, these protocols did not noticeably change any of the staining pattern and were not followed throughout the study.

\section{Results}

\section{Specificities of the antibodies and immunostaining}

Monoclonal antibodies MC-I and MC-II were previously characterized (Huang et al., 1986a) to react specifically with type I and II PKC, respectively. These antibodies do not recognize type III PKC by immunoblot analysis or immunoprecipitation. We have not obtained an antibody-producing clone that recognizes type III PKC. Monospecific antibodies MS-I, -II, and -III prepared from the unfractionated polyclonal antibodics were also specific for their respective isozyme as described (Huang et al., 1987a). In the present study, these antibodies were used at a dilution equivalent to 10 - to 20,000 -fold of the original unfractionated immune serum. At these dilutions, these purified. antibodies could detect $10-20 \mathrm{ng}$ of purified rat brain PKC isozymes in immunoblot analysis. Ascites fluids of MC-I and MC-II were used at a dilution of 2000-fold throughout the study, though up to 10,000 -fold dilution was effective in the staining of cerebellum. All of these isozyme-specific antibodies produced specific stainings that were not observed with preimmune and normal goat sera or normal mouse IgG. Most importantly, no distinctive staining was observed when these antibodies were pretreated with their corresponding types of $\mathrm{PKC}$ isozyme and no longer gave positive signals against $50 \mathrm{ng}$ of the purified isozyme by immunoblot analysis.

\section{Regional distribution of PKC isozymes in rat brain}

All PKC immunoreactivities were widely distributed throughout the various regions of rat brain. In coronal sections through the level of rostral hippocampus, staining with either MS-I, -II, or -III (Fig. 1, $A, C, B$, respectively, each shows a portion of the area) all indicated that immunoreactivities were most concentrated in neocortex, hippocampal formation, and various amygdaloid nuclei, less prominent in tail of caudate, thalamus, and hypothalamus, and least in internal capsule, corpus callosum, and other fiber tract-enriched areas. At this low magnification, it was obvious that the immunoreactivity was much lower in the molecular layer of cortex (also see Figs. 2 and 3), and in the neuropil of hippocampus and molecular layer of dentate gyrus (Figs. 1, 4). The general distribution of the immunoreactivities resembled that of a Nissl-stained brain section and strongly suggested the association of the PKC immunorcactivity with the neuronal somata. In several cortical areas, the gross laminar distribution of the type III PKC-positive neurons exhibited a somewhat higher density than those of type I and II PKCs, as shown in the subsequent figures at higher magnification.

\section{Distribution of PKC isozymes in frontal cortex}

In cortex of the retrosplenial region in cingulate gyrus (Fig. $2 A$ ), type III PKC immunoreactivities were associated mainly with neuronal somata. There was a lack of staining of cells in layer I (Fig. 2A). Serial sections stained with either MS-I or MC-I, MS-II or MC-II (data not shown) also revealed cell body immunoreactivities, albeit to slightly lesser densities, particularly in layer II. This general distribution pattern extended into frontal cortex (Fig. 2, $B-D$ ), where the molecular layer was again devoid of staining regardless of which antibody was used. With MS-III (Fig. 2D), a high density of neurons were stained throughout layers II-VI. At higher magnification, the densely packed cells in layer II of MS-III-stained section resembled both small pyramidal and granule cells in morphology (Fig. $2 E$ ). The same type of cells was also stained when type I and II PKC specific-antibodies were used; the medium-sized and large pyramidal cells in deeper layers were especially prominent with all antibody staining. While the immunoreactivity was most strongly associated with neuronal somata, a segment of the positively stained apical dendrites of these pyramidal cells was also detectable (Fig. 2, $F-H$ ) being especially prominent when stained by the type I-specific antibodies, both MS-I and MC-I (Fig. 2F). Interestingly, the type III PKC-like immunoreactivity seemed to associate predominantly with the cytoplasm of the somata, as indicated in Figure $2 \mathrm{H}$ at a higher magnification. In contrast, both type I and II PKC-associated immunoreactivities appeared to reside in the whole somata, and the staining was somewhat patchy and granular, as shown in Figure $2 G$ of a MC-II stained section.

\section{Distribution of PKC isozymes in other areas of cerebral cortex}

All $3 \mathrm{PKC}$ isozymes were also present in other cortical areas (Fig. 3), and type III PKC-positive neurons appeared to be the 

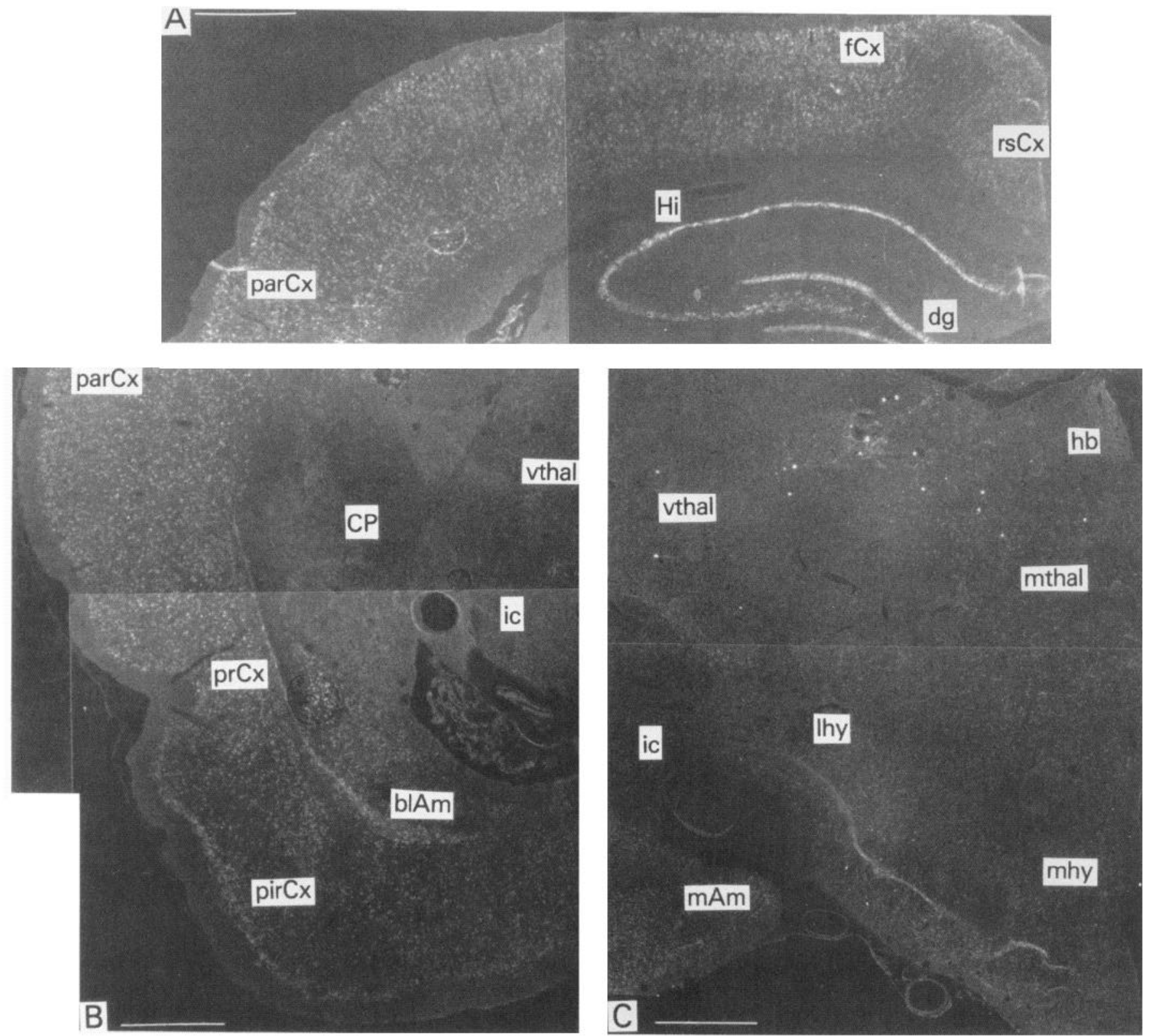

Figure 1. Immunocytochemical localization of protein kinase $\mathrm{C}$ isozymes in coronal sections of rat brain at the level of rostral hippocampal formation. Serial sections were stained with MS-I $(A)$, MS-III $(B)$, and MS-II $(C)$, and only portions of the sections are shown. Generally, the immunoreactivities are associated with neurons, stronger in telencephalic than in diencephalic structures, weakest in molecular layer of neocortex and neuropil-rich areas. $b l A m$, basolateral amygdaloid nucleus; $r s C x$, retrosplenial cortex of cingulate gyrus; $c p$, tail of caudatoputaman; $d g$, dentate gyrus; $f C x$, frontal cortex; $h b$, habenula; $H i$, hippocampus; $i c$, internal capsule; lhy, lateral hypothalamus; $m A m$, medial amygdaloid nucleus; $m h y$, medial hypothalamus; mthal, medial thalamus; $\operatorname{par} C x$, parietal cortex; pirCx, piriform cortex; prCx, perirhinal cortex; vthal, ventral thalamus. MC-I and MS-I, and MC-II and MS-II give similar staining pattern (see subsequent figures at higher magnifications). Scale bars, $1 \mathrm{~mm}$.

most abundant (Fig. 3, $A, D$ ), especially in layer II of piriform cortex (Fig. 3, $D, F$ ). The densely packed, MS-III positive pyramidal cells of layer II of piriform cortex showed predeminant presence of this kinase in the cytoplasm and the initial segment of the apical dendrite (Fig. $3 F$ ). Even at low magnification, the cytoplasmic localization of type III PKC within the spindleshaped neurons in deeper layers of perirhinal cortex (Fig. 3C) and the triangle-shaped neurons in the medial amygdaloid nucleus (Fig. $3 I$ ) were obvious. In contrast to type III PKC's cytoplasmic localization, both type I and II PKCs were present in the entire somata, based on the staining with both monoclonal and monospecific antibodies (Fig. 3, $B, E, G, H$ ).

\section{Distribution of PKC isozymes in hippocampus and dentate gyrus}

The hippocampal formation is one of the most strongly stained regions by the various $\mathrm{PKC}$ antibodies (Fig. 1). The immunoreactivities for all 3 types of PKC were present and confined largely to hippocampal pyramidal cells and to granule cells of the dentate gyrus and were much less in cells of the strata oriens, radiatum, and lacunosum moleculare, and molecular layer of the dentate gyrus. Granule cells in the dentate gyrus were stained by type I (Fig. 1), type II (Fig. 4A), and type III (Fig. $4 B$ ) specific antibodies. While immunoreactivities of type I and II PKCs 

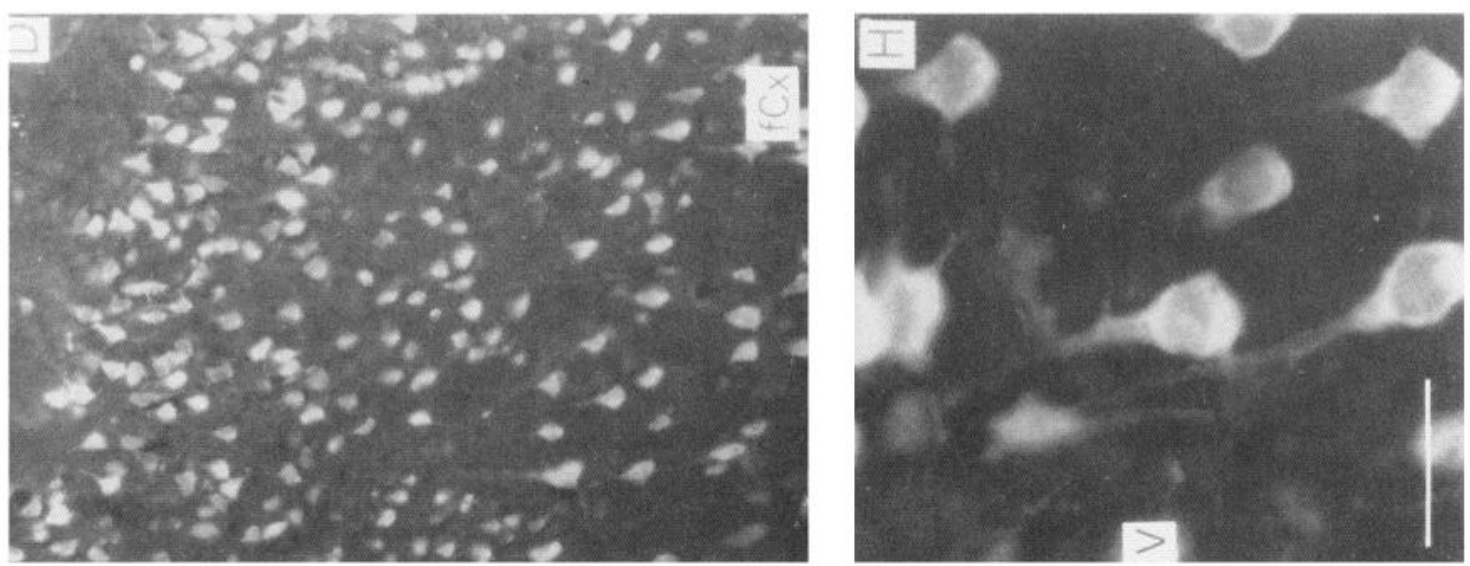

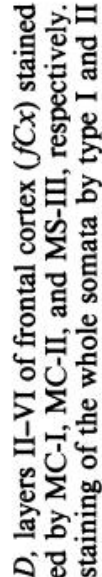
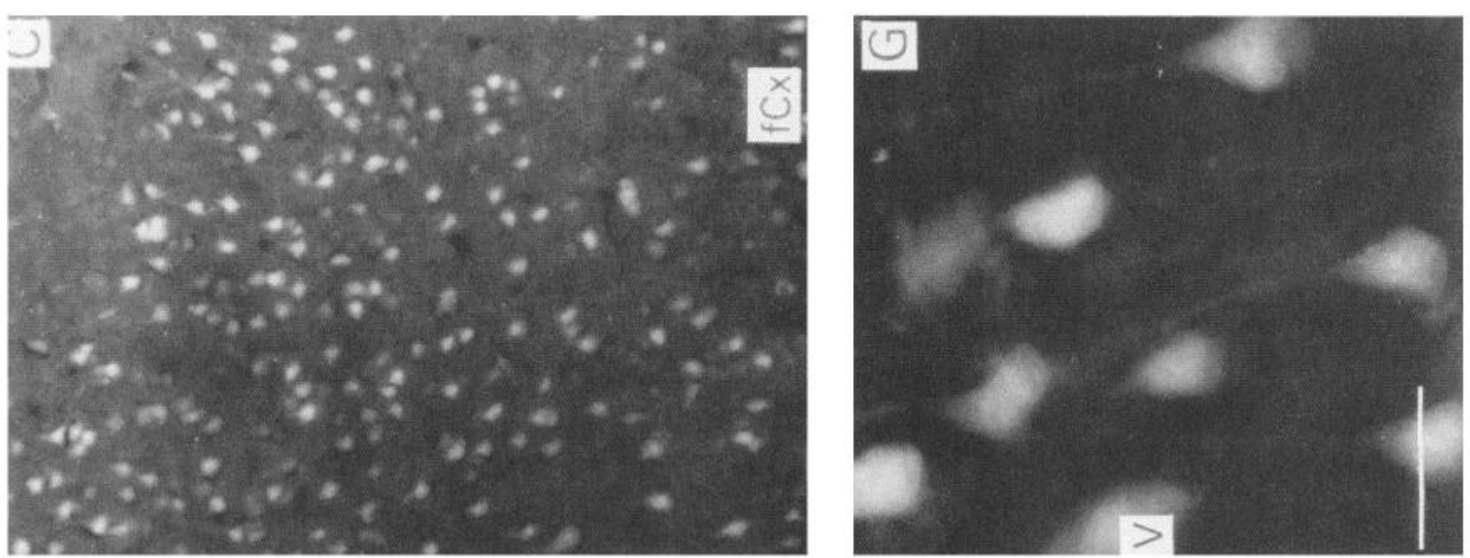

A. के

急要

严?

空影

훈

品

犽

정.

प⿺

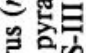

政

和里

㖊完

ㄷํㅇํํ

喓会

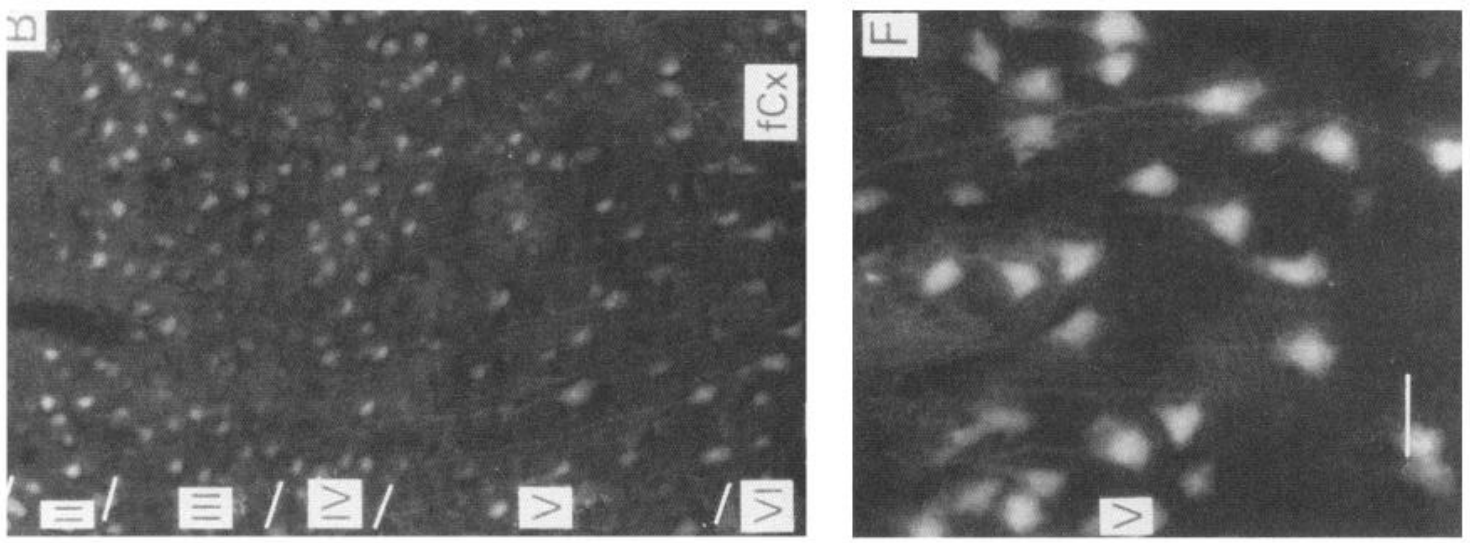

ㅁ․ㄹ

o.

. तु

토은

究记

实

४⿻

$8=$

ב응

政

잉

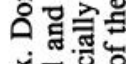

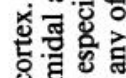
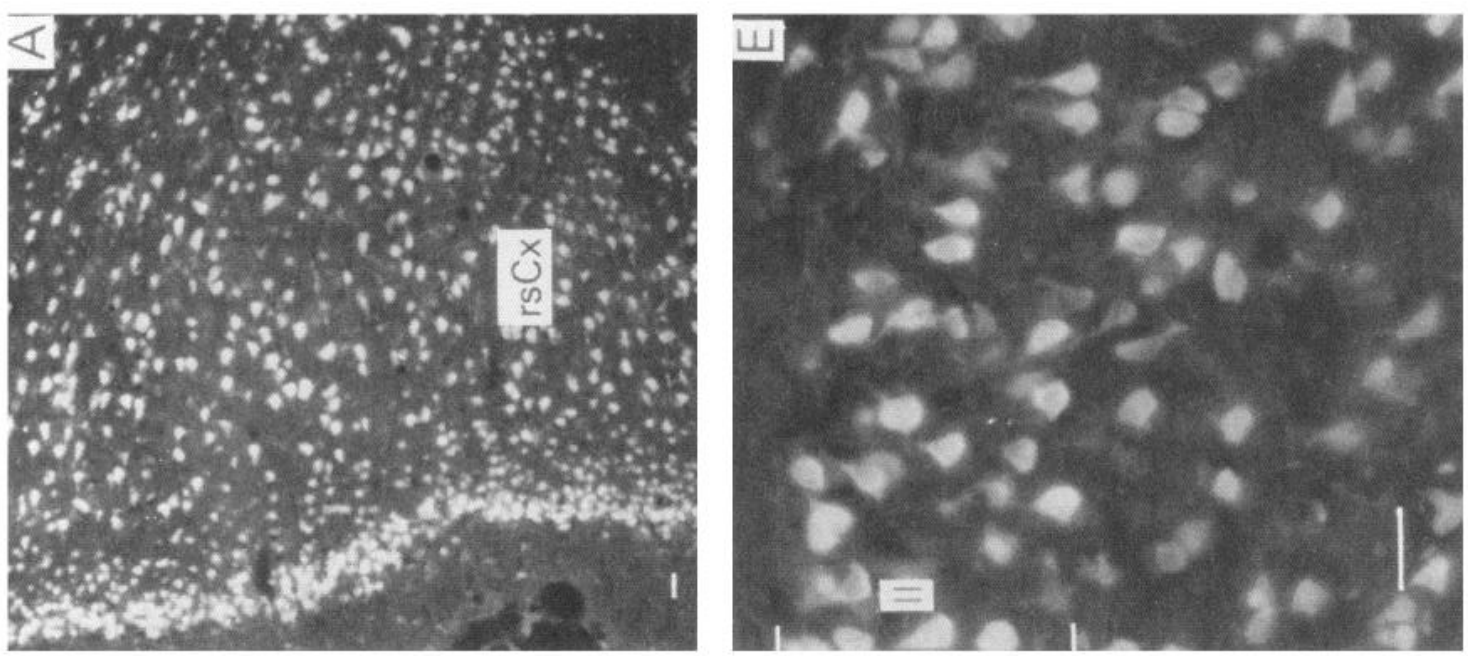

댄

즐

幽导.

프워

4 .

政

,

o

的方

年

论

드원

호음

코웛

赵영

견

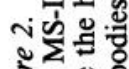

害告

影星 

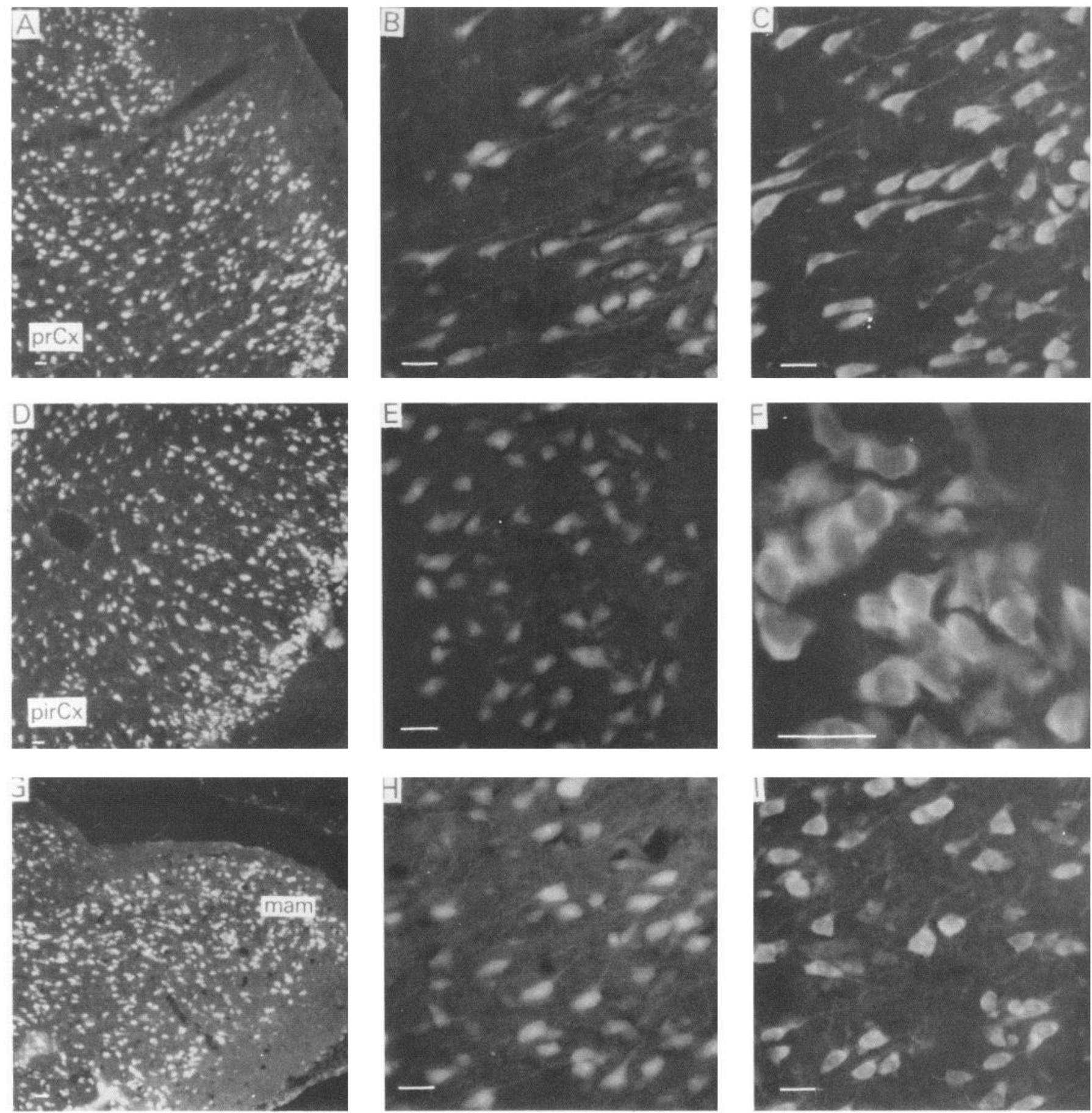

Figure 3. Localization of PKC isozymes in perirhinal and piriform cortices and amygdala. Dorsal is up. $A-C$, Perirhinal cortex ( $p r C x$ ) stained by MS-III $(A)$, MS-I $(B)$, and MS-III $(C)$. $D-F$, Piriform cortex $(p i r C x)$ stained by MS-III $(D)$, MC-II $(E)$, and MS-III $(F)$. $G-I$, Medial amygdaloid complex $(\mathrm{mam})$ stained by MC-I $(G)$, MS-II $(H)$, and MS-III $(I)$. Note the lack of staining at superficial layer, the staining of apical dendrites, and the cytoplasmic staining of the MS-III positive neurons. Scale bars, $15 \mu \mathrm{m}$.

covered the whole granule cells, that of type III PKC was in the cytoplasm (Fig. 4C). Pyramidal cells in CA1-CA3 and those in hilus of dentate gyrus were also heavily stained by all 3 types of antibodies. Type I-specific antibodies appeared to stain the 3-4 superficial rows of pyramidal cells, while both type II and III PKC antibodies stained cells throughout the entire thickness (compare Fig. 4, D,E). Type III PKC antibody also recognized many more cells, resembling pyramidal cells, than type I and II PKC antibodies in the hilus of the dentate gyrus (Fig. 4, $H$,
I). In these cells, type III PKC immunoreactivities were concentrated in the cytoplasm (Fig. 4, $G, K$ ), whereas the immunoreactivities of type I and II PKC spread over the somata of these neurons (Fig. $4, F, J$ ) in a patchy and granular fashion.

\section{Distribution of PKC isozymes in the olfactory bulb}

Previously, immunoblot analysis showed that the olfactory bulb has a higher level of type III PKC per unit cellular protein than those of the other 2 PKCs. In the present immunofluorescent 
staining study, MS-III showed stronger reactivities than those of type I and II PKC antibodies; even using the latter 2 antibodies at lower dilution did not improve the staining significantly. These antibodies stained mainly the periglomerular and internal granular cells as illustrated by the staining with MC-II (Fig. 5A). In addition, the MS-III also stained the mitral cell layer which lies between the internal granule cells and the external plexiform layer (Fig. $5, B-D$ ). These mitral cells constitute the main olfactory efferent pathway into the cortical area and were only poorly recognized by type I or II PKC antibodies. Cells in the neuropil-rich external plexiform layer were infrequently recognized by any of the antibodies tested.

\section{Distribution of PKC isozymes in cerebellum}

Previously (Huang et al., 1987b), using monospecific antibodies, we observed that the 3 types of PKC isozymes were most distinctly localized in different cell layers of cerebellum, i.e., type I PKC in Purkinje cells and their dendrites, type II PKC in granule cells, and type III PKC in both granule and Purkinje cells but not in the latter's dendrite. In the present study, we employed MC-I and MC-II for the staining, and essentially the same results were obtained. Figure $6, A, D$, shows the staining of Purkinje cells and their dendrites by MC-I; Figure $6, B, E$, shows the staining of granule cells by MC-II. Since the monoclonal antibody for type III PKC was not available in our laboratory, ${ }^{3}$ staining of both granule and Purkinje cells by MS-III is shown in Figure 6, $C, F$. Though type I PKC antibodies stained the cell body and dendrite of Purkinje cell, there was no obvious staining in the axon of these cells either in granule cell layer or into the white matter. Furthermore, no obvious staining of basket or stcllate cclls in the molccular laycr or other cell types in the granule layer was observed when type I PKC antibodies were used. In contrast, some apparent basket or stellate cells or both were also found stained by type II and III PKC antibodies. At the light microscopic level, processes of these cells were not evidently stained by any of these antibodies. Though, Purkinje cells were stained by both type I and III antibodies, only type I PKC was found present in their dendritic trees.

Staining of other coronal sections rostral and caudal to that in Fig. 1 also revealed the abundant presence of PKC isozymes in other regions of brain (detailed staining patterns will be published separately). Both large and medium sized neurons in caudatoputaman were also recognized by PKC antibodies while the interposed nerve bundles were not. Neurons in the habenula and substantia nigra were also stained, especially by type II and III antibodies. The fiber tracts including all the astroglial structurcs constituted the lcast staincd matcrials, with only weak staining occasionally found in corpus callosum and white matter of cerebellum.

\section{Discussion}

The present study, using the well-characterized PKC isozymespecific antbodies, offers a mapping of the regional and cellular distributions of 3 PKC isozymes in selected rat brain regions. Both monoclonal and polyclonal monospecific antibodies were

\footnotetext{
${ }^{3} \mathrm{~A}$ monoclonal antibody for type III PKC is not available in our laboratory. $\mathrm{At}$ the completion of this work, such an antibody was given to us by Dr. Karen Leach of The Upjohn Company. In immunoblot analysis, this antibody was found to recognize our purified rat brain type III PKC and not the other 2 isozymes. In test staining, this antibody stained both Purkinje and granule cells of cerebellum and periglomerular, mitral, and internal granule cells of the olfactory bulb similar to the staining patterns obtained with our MS-III. We would like to express our gratitude to Dr. Leach for providing this antibody.
}

employed in the study. Though the monospecific antibodies recognize epitopes on both catalytic and phorbol ester binding domains of PKC (Huang and Huang, 1986; Huang et al., 1987a), and monoclonal antibodies recognize epitopes on the latter domains only (Nakabayashi and Huang, 1988), both monoclonal and monospecific antibodies, including type I and II gave similar patterns of staining. For example, in the cerebellum, both MC-I and MS-I stained the Purkinje cells and their dendrites where $\gamma$ PKC gene transcripts were located; and both MC-II and MSII stained the granule cells where $\beta$ PKC gene transcripts were detected (Brandt et al.,1987). These monospecific antibodies have also been used in identifying the expressed $\mathrm{PKC}$ isozymes of various PKC gene-transfected COS cells and established that PKC $\alpha$ gene codes for type III PKC, $\beta$ gene for type II PKC, and $\gamma$ gene for type I PKC (Huang et al., 1987b). Thus, these antibodies are suitable for the immunocytochemistry in that they directly reveal the location of each PKC gene product.

It is clear from the present light microscopic examination that PKC immunoreactivities are present in diverse structures of brain and are most concentrated in neuronal somata and dendrites. Except for Purkinje and granule cells in the cerebellum (see last paragraph), and mitral cells in the olfactory bulb, most types of neuron appear to contain all 3 types of PKC. However, this study was not designed to examine the colocalization of PKCs within individual cells; investigation using a double-labeling procedure would be more appropriate. Previously, Worley et al. (1986), using phorbol ester binding autoradiography, also demonstrated the abundant presence of phorbol ester receptors, assumed to be $\mathrm{PKC}$, in various brain regions. Though phorbol ester binding did not differentiate specific isozymes of PKC, the major phorbol ester binding activitics were found to reside in the synaptic rich neuropil, such as the striata oriens and radiatum of the hippocampus and layer I of the neocortex, where we found little PKC immunoreactivity (present study). Cell bodies of some well-identified neurons, such as cortical and hippocampal pyramidal cells, granule cells of the dentate gyrus, and Purkinje and granule cells of the cerebellum, where the PKC immunoreactivities were localized in the present study, were found to be devoid of any phorbol ester binding activity. However, from the lesion studies, Worley et al. (1986) concluded that the phorbol ester binding sites in the stratum oriens of hippocampus derived from pyramidal cells and those in the molecular layer of cerebellum associated with dendrites of the Purkinje cells. Thus, the major difference is that the present immunohistochemistry detects PKC in cell bodies, while the autoradiography reveals proteins in cell processes. Several factors could account for these discrepancies. Binding of phorbol ester to PKC is known to depend on the presence of phospholipid and calcium (Castagna et al, 1982); PKC in cell bodies and proximal dendrites may not bind phorbol ester in the environment of the aforementioned phorbol ester autoradiographic procedure. Alternatively, the cytoplasmically bound ligands tend to be washed away so that the autoradiographic images involved mainly the membrane-bound ligands. On the other hand, our immunohistochemical procedure may not detect PKC in neuropil due to inaccessibility of the antigenic sites in the membrane. However, using detergent to facilitate the penetration of antibody during incubation did not change any of the staining pattern.

Kuo and his colleagues (Girard et al., 1985; Wood et al., 1986), using their polyclonal antibodies, have localized $\mathrm{PKC}$ in rat brain immunocytochemically. They observed strong presyn- 

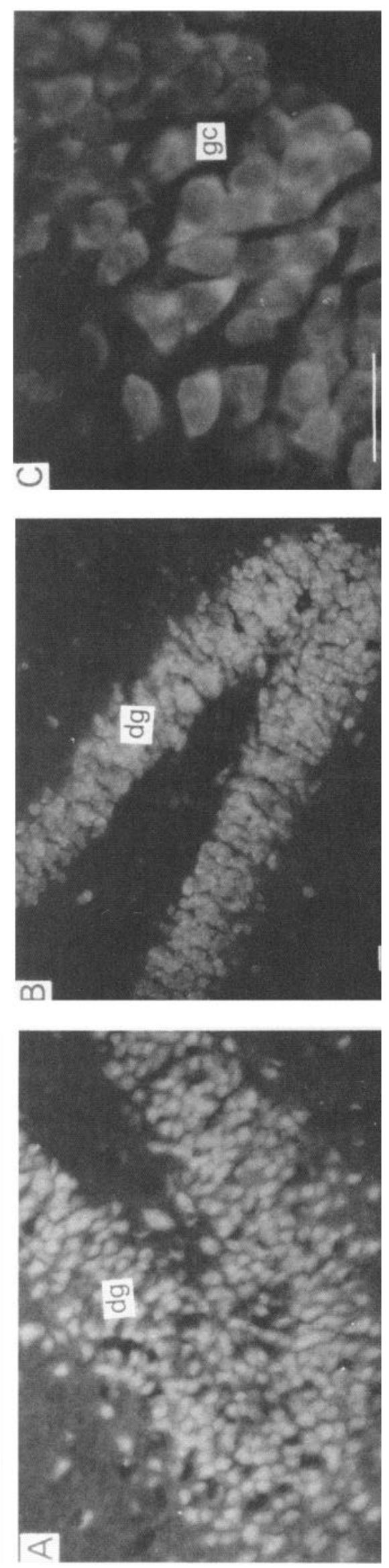
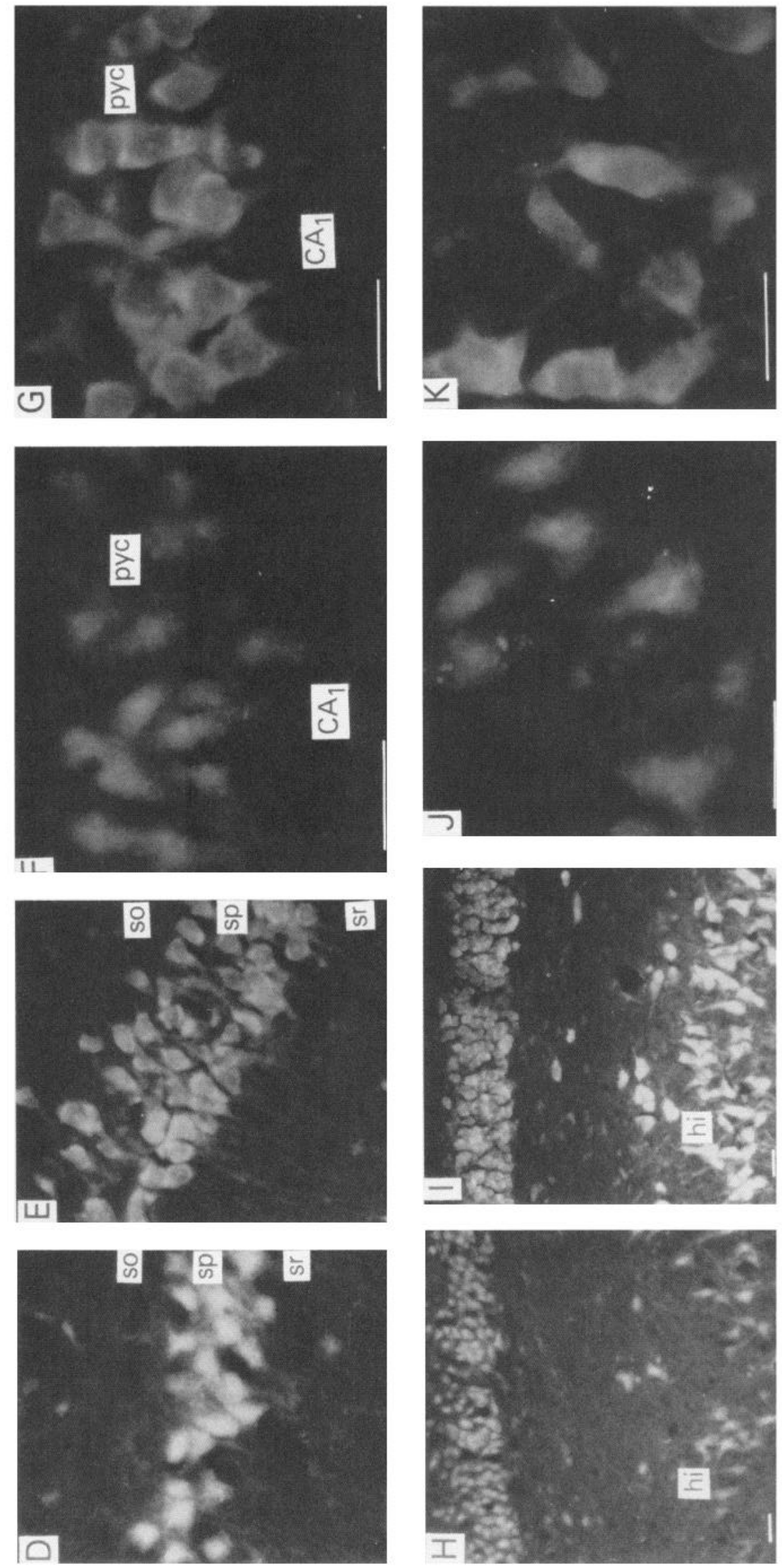

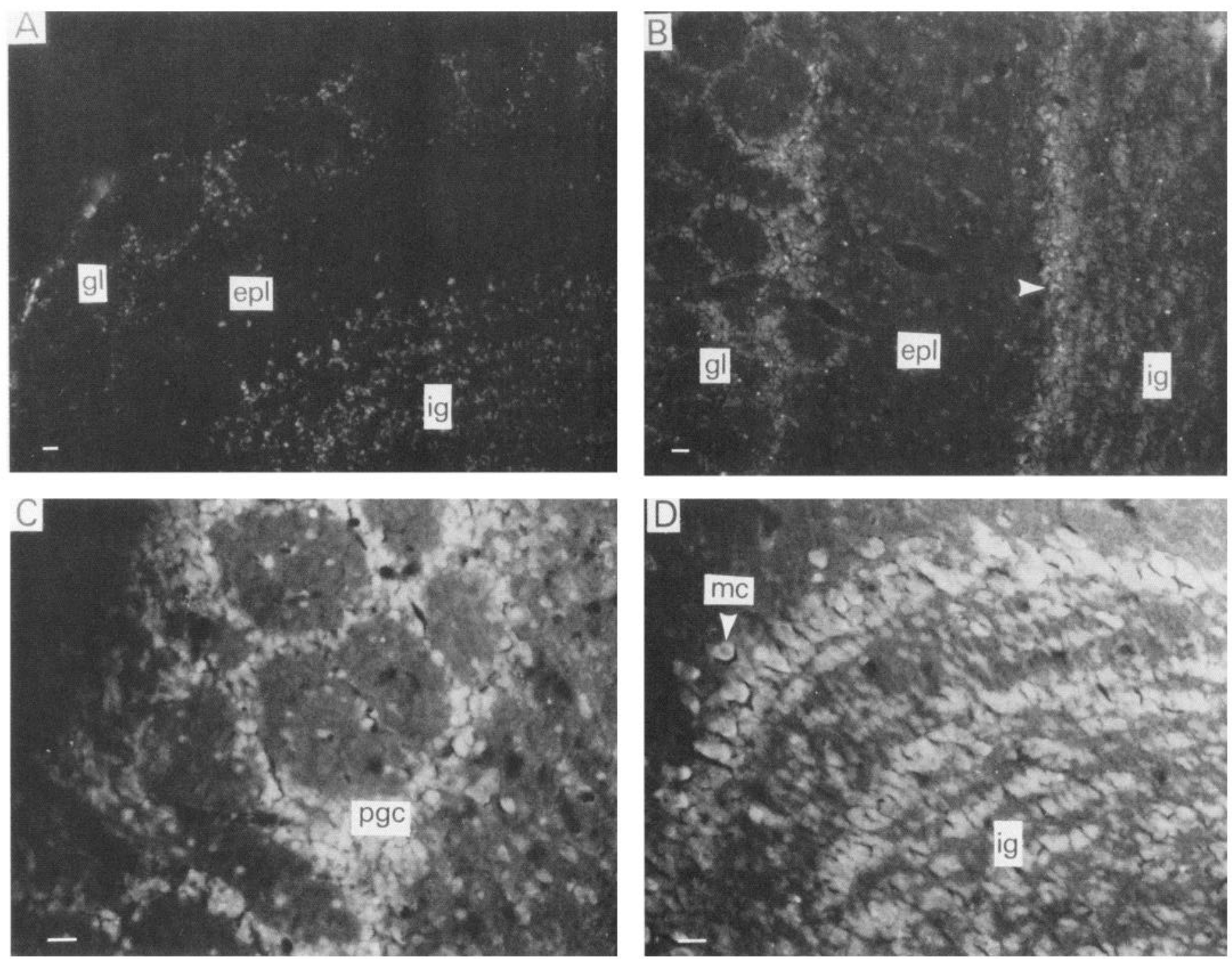

Figure 5. Localization of PKC isozymes in the olfactory bulb. Staining of glomerular layer $(\mathrm{g} l)$, and internal granule cells $(\mathrm{ig})$ by MC-II $(A)$ and MS-III $(B-D) . p g c$, periglomerular cells; $m c$, mitral cells; epl, external plexiform layer. MS-III also stained the mitral cells (arrowhead). Scale bars, $15 \mu \mathrm{m}$.

aptic association of PKC (axon and synaptic terminal) and prominent perinuclear staining of Purkinje and hippocampal pyramidal cells, but their antibodies revealed little dendritic staining. These antibodies, though able to recognize the native $80 \mathrm{kDa}$ species of purified rat brain PKC, were not tested for their reactivities toward all 3 PKCs or any of them. Also, these antibodies appeared to recognize a $67 \mathrm{kDa}$ protein in rat brain extract and not the $80 \mathrm{kDa}$ species of PKC in the immunoblot analysis (Girard et al., 1985). Thus, their detection of a different species of PKC that was not recognized by our type-specific antibodies may account for the differences between their results and the present ones. However, their observation of nuclear association of PKC deserves some attention. We noticed mainly cytoplasmic staining by type I and III PKC antibodies in Purkinje cells and by type III PKC antibody in pyramidal cells of the cortex and hippocampus and granule cells of the dentate gyrus, whereas staining by type I and II PKC antibodies was not confined to cytoplasm of these latter neurons. Although the present light microscopic examination did not unequivocally prove PKC I and II's nuclear associations, such a notion is suggested, however. With immunoblot analysis for subcellular localization of PKC isozymes in cerebrum (Yoshida et al., 1988), we also noticed that majority of type III PKC was cytosolic, whereas majority of type I and II PKCs were associated with various membranous fractions including the nucleus.

Using several monoclonal antibodies for immunocytochem-

Figure 4. Localization of PKC isozymes in hippocampus and the dentate gyrus. $A$ and $B$, Dentate gyrus $(d g)$ stained by MS-II $(A)$ and MS-III $(B)$. $C$, Staining of granule cells $(g c)$ by MS-III is mostly cytoplasmic. $D-G$, Hippocampal pyramidal cells $(p y c)$ at CAl stained by MS-I $(D)$, MSIII $(E$ and $G$ ), and MC-II $(F)$. so, stratum oriens; $s p$, stratum pyramidale; $s r$, stratum radiatum. $H-K$, Pyramidal cells of hilus $(h i)$ with ectal limb $(H$ and $I)$ of the dentate gyrus stained with MC-I $(H)$, MS-III $(I$ and $K)$, and MS-II $(J)$. Staining of pyramidal cells by MS-III is cytoplasmic; in contrast, type I and II antibodies stain the entire cells. Scale bars, $15 \mu \mathrm{m}$. 

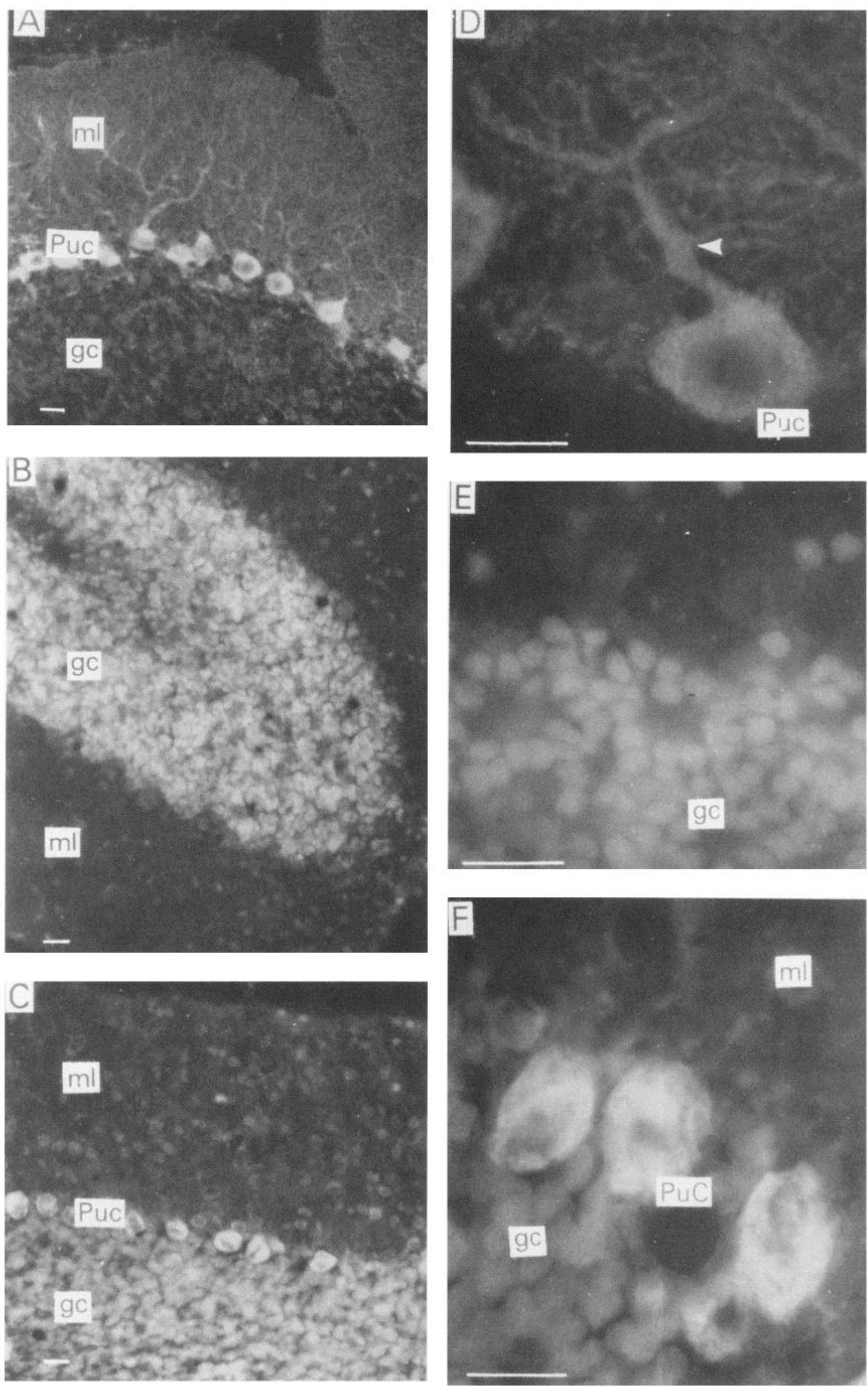

Figure 6. Localization of PKC isozymes in cerebellum. $A$ and $D$, Staining of Purkinje cells $(P u c)$ and dendrites (arrowhead) by MC-I. B and $E$, Staining of granule cells $(\mathrm{gc})$ by MC-II. $C$ and $F$, Staining of Purkinje and granule cells by MS-III. $m l$, molecular layer. Scale bars, $15 \mu \mathrm{m}$. 
ical localization of PKC Mochly-Rosen et al. (1987) observed a distinctive distribution pattern of reaction product for each of their antibodies. While one of these antibodies stained dendrites of Purkinje and cortical pyramidal cells, other antibodies stained astroglial structures, with neuronal somata only very poorly stained. Even though some of these antibodies have been tested for their inhibition of PKC (Mochley-Rosen and Koshland, 1987), information concerning the immunocharacterization (immunoblot or immunoprecipitation) and isozyme specificity of these antibodies is not available, and comparison with our present results is presently not possible. It is interesting to note that our antibodies stain the astrocytes in brain sections poorly and do not recognize them in the dissociated cell cultures of cerebellum (F. L. Huang, D.-M. Chuang, and K. P. Huang, unpublished observations). Cell body and dendritic staining of Purkinje cells were recently reported by Nishizuka and his coworkers (Kitano et al., 1987) by a combination of 3 of their monoclonal antibodies. Though these antibodies all recognized the purified native $82 \mathrm{kDa}$ rat brain $\mathrm{PKC}$, their isozyme specificities were not determined. Judging from their specific staining of Purkinje cells in cerebellum, they undoubtedly would all specifically react with type I or $\gamma$ PKC.

It is generally believed that calcium and calcium-dependent phosphorylation play important roles in neuronal function. The 2 major calcium-dependent kinases identified in brain are calcium/calmodulin-dependent protein kinasc II and PKC. Immunocytochemical localization of the former using antibodies to either calmodulin (Wood et al., 1980) or subunits of the enzyme (Ouimet et al., 1984) has been shown to concentrate in neuronal somata and dendrites. The present data indicated that PKC located similarly as calcium/calmodulin-dependent kinase II in the CNS and suggested the possibility of some common functional role for these calcium-dependent kinases such as in neuronal plasticity (Smith, 1987). In vitro both enzymes have been found to be regulated through autophosphorylation (Huang et al., 1986b; Lai et al., 1986). Though they all depend on calcium, the differences in calmodulin and phospholipid requirements signify their unique regulatory action. Their exact role in the CNS must await the identification of the physiological target substrates. Toward this end, it is interesting to note that synapsin I (thought to be phosphorylated by calcium/calmodulin-dependent kinase) and $\mathrm{B}-50$ protein ( $\mathrm{F} 1$, by $\mathrm{PKC}$ ) were both localized in nerve terminals or the presynaptic compartment (DeCamilli et al., 1979; Oestreicher and Gispen, 1986). In the cerebellum, localization of type I PKC in Purkinje cells (present study) appeared to be similar to that of cGMP-dependent protein kinase (DeCamilli et al., 1984). Recently, a cGMPdependent ion channel was described (Cook et al., 1987; Matesic and Liebman, 1987), and there was evidence that in vitro guanylate cyclase could be phosphorylated and activated by PKC (Zwiller et al., 1985). It is likely that PKC may regulate the cGMP-mediated responses.

The presence of all 3 types of PKC isozymes in many neuronal cell types in cerebrum is interesting. No special effort was taken in the present study to determine the relative intensity of staining of each isozyme in neurons of any given region. Previous immunoblot analysis, however, indicated that relative contents of these isozymes varied among different regions (Huang et al., 1987a). These data imply that for any given region or neuron, each isozyme is probably involved in a specialized function. Furthermore, the differential subcellular distributions of these isozymes also suggest a unique functional role for each isozyme at different locales within neurons. For example, both type I and III PKC are present in Purkinje cells of cerebellum, while only type I PKC is present in the dendrites of these cells (Fig. 6). If both of these kinases are involved in signal transduction, type I PKC may play a larger role distal to the cell body. Type III PKC is mostly cytoplasmic in cortical and hippocampal pyramidal cells and granule cells of the dentate gyrus, whereas type I and II PKC may also associate with subcellular organelles that include nuclei (Figs. 2-4). Thus, type I and II PKCs would likely be candidates in controlling nuclear events.

In conclusion, the present results give a detailed account of the cellular localizations of 3 types of PKC isozymes in various identified regions of rat brain. This information may aid in identifying the relevant phosphorylation target for PKC in neuronal functions.

\section{References}

Akers, R. F., D. Lovinger, P. Colley, D. Linden, and A. Routtenberg (1986) Translocation of protein kinase $\mathrm{C}$ activity may mediate hippocampal long-term potentiation. Science 231: 587-589.

Baraban, J. M., S. H. Snyder, and B. E. Alger (1985) Protein kinase $\mathrm{C}$ regulates ionic conductance in hippocampal pyramidal neurons: Electrophysiological effects of phorbol esters. Proc. Natl. Acad. Sci. USA 82: 2538-2542.

Berridge, M. J., and R. F. Irvine (1984) Inositol triphosphate, a novel second messenger in cellular signal transduction. Nature 312: 315 321.

Brandt, S. J., J. E. Niedel, R. M. Bell, and W. S. Young, III (1987) Distinct patterns of expression of different protein kinase $C$ mRNAs in rat tissues. Cell 49: 57-63.

Castagna, M., Y. Takai, K. Kaibuchi, K. Sano, U. Kikkawa, and Y. Nishizuka (1982) Direct activation of calcium-activated, phospholipid-dependent protein kinase by tumor-promoting phorbol esters. J. Biol. Chem. 257: 7847-7851.

Cook, N. J., W. Hanke, and V. B. Kaupp (1987) Identification, purification, and functional reconstitution of the cyclic CMP-dependent channel from rod photoreceptors. Proc. Natl. Acad. Sci. USA 84: 585-589.

Coussens, L., P. J. Parker, L. Rhee, T. L. Yang-Feng, L. Chen, M. D. Waterfield, V. Francke, and A. Ullrich (1986) Multiple, distinct forms of bovine and human protein kinase $\mathrm{C}$ suggest diversity in cellular signaling pathways. Science 233: 859-866.

DeCamilli, P., T. Ueda, F. E. Bloom, E. Battenberg, and P. Greengard (1979) Widespread distribution of protein $I$ in the central and peripheral nervous systems. Proc. Natl. Acad. Sci. USA 76: 5977-5981.

DeCamilli, P., P. E. Miller, P. Levitt, U. Walter, and P. Greengard (1984) Anatomy of cerebellar Purkinje cells in the rat determined by a specific immunohistochemical marker. Neuroscience 11: 761817.

Girard, P. R., J. Mazzei, J. G. Wood, and J. F. Kuo (1985) Polyclonal antibodies to phospholipid/ $\mathrm{Ca}^{2+}$-dependent protein kinase and immunocy tochemical localization of the enzyme in rat brain. Proc. Natl. Acad. Sci. USA 82: 3030-3034.

Huang, K.-P., and F. L. Huang (1986) Immunochemical characterization of rat brain protein kinase C. J. Biol. Chem. 261: 1478114787.

Huang, K.-P., H. Nakabayashi, and F. L. Huang (1986a) Isozymic forms of rat brain $\mathrm{Ca}^{2+}$-activated and phospholipid-dependent protein kinase. Proc. Natl. Acad. Sci. USA 83: 8535-8539.

Huang, K.-P., K.-F. J. Chan, T. J. Singh, H. Nakabayashi, and F. L. Huang (1986b) Autophosphorylation of rat brain $\mathrm{Ca}^{2+}$-activated and phospholipid-dependent protein kinase. J. Biol. Chem. 261: $12134-12140$.

Huang, F. L., Y. Yoshida, H. Nakabayashi, and K.-P. Huang (1987a) Differential distribution of protein kinase $\mathrm{C}$ isozymes in the various regions of brain. J. Biol. Chem. 262: 15714-15720.

Huang, F. L., Y. Yoshida, H. Nakabayashi, J. L. Knopf, W. S. Young, III, and K.-P. Huang (1987b) Immunochemical identification of protein kinase $C$ isozymes as products of discrete genes. Biochem. Biophys. Res. Commun. 149: 946-952. 
Inoue, M., A. Kishimoto, Y. Takai, and Y. Nishizuka (1977) Studies on a cyclic nucleotide-independent kinase and its proenzyme in mammalian tissues. J. Bio. Chem. 252: 7610-7616.

Jaken, S., and S. C. Kiley (1987) Purification and characterization of three types of protein kinase $\mathrm{C}$ from rabbit cytosol. Proc. Natl. Acad. Sci. USA 84: 4418-4422.

Kitano, T., T. Hashimoto, U. Kikkawa, K. Ase, N. Saito, C. Tanaka, Y. Ichimori, K. Tsukamoto, and Y. Nishizuka (1987) Monoclonal antibodies against rat brain protein kinase $\mathrm{C}$ and their application to immunocytochemistry in nervous tissues. J. Neurosci. 7: 1520-1525.

Knopf, J. L., M.-H. Lee, L. A. Sultzman, R. W. Krig, C. R. Loomis, R. M. Hewick, and R. M. Bell (1986) Cloning and expression of multiple protein kinsae $C$ cDNAs. Cell 46: 491-502.

Kuo, J. F., R. G. G. Anderson, B. C. Wise, L. Mackerlova, I. Salomonsson, N. Brackett, N. Katoh, M. Shoji, and R. W. Wrenn (1980) Calcium-dependent protein kinase: Widespread occurrence in various tissues and phyla of the animal kingdom and comparison of effects of phospholipid, calmodulin, and trifluoperazine. Proc. Natl. Acad. Sci. USA 77: 7039-7043.

Lai, Y., A. C. Nairn, and P. Greengard (1986) Autophosphorylation reversibly regulates the $\mathrm{Ca}^{2+}$-/calmodulin-dependence of $\mathrm{Ca}^{2+} / \mathrm{cal}$ modulin-dependent protein kinase II. Proc. Natl. Acad. Sci. USA 83: 4253-4257.

Madison, D. V., R. C. Malenka, and R. A. Nicoll (1986) Phorbol esters block a voltage sensitive chloride current in hippocampal pyramidal cells. Nature 321: 695-697.

Malenka, R. C., D. V. Madison, and R. A. Nicoll (1986) Potentiation of synaptic transmission in the hippocampus by phorbol esters. $\mathrm{Na}$ ture $321: 175-177$.

Malenka, R. C., G. S. Ayoub, and R. A. Nicoll (1987) Phorbol esters enhance transmitter release in rat hippocampal slices. Brain Res. 403: 198-203.

Matesic, D., and P. A. Liebman (1987) cGMP-dependent cation channel of retinal rod outer segments. Nature 326: 600-603.

Mochley-Rosen, D., and D. E. Koshland, Jr. (1987) Domain structure and phosphorylation of protein kinase C. J. Biol. Chem. 262: 22912297.

Mochley-Rosen, D., A. I. Basbaum, and D. E. Koshland, Jr. (1987) Distinct cellular and regional localization of immunoreactive protein kinase $C$ in rat brain. Proc. Natl. Acad. Sci. USA 84: 4660-4664.

Nakabayashi, H., and K.-P. Huang (1988) Monoclonal antibodies against type II rat brain protein kinase C. J. Biol. Chem. 263: 298304

Nishizuka, Y. (1984) The role of protein kinase $C$ in cell surface signal transduction and tumor promotion. Nature 308: 693-698.
Nishizuka, Y. (1986) Studies and perspectives of protein kinase C Science 233: 305-312.

Oestreicher, A. B., and W. H. Gispen (1986) Comparison of the immunocytochemical distribution of the phosphoprotein B-50 in the cerebellum and hippocampus of immature and adult rat brain. Brain Res. 375: 267-279.

Ohno, S., H. Kawasaki, S. Imajoh, M. Inagaki, H. Yokokura, T. Sakoh, and H. Hidaka (1987) Tissue-specific expression of three distinct types of rabbit protein kinase C. Nature 325: 161-166.

Olmsted, J. B. (1981) Affinity purification of antibodies from diazotized paper blots of heterogeneous protein samples. J. Biol. Chem. 256: 11955-11957.

Ono, Y., T. Kurokawa, T. Fujii, K. Kawahara, K. Igarashi, V. Kikkawa, K. Ogita, and Y. Nishizuka (1986) Two types of complementary DNAs of rat brain protein kinase C. FEBS Lett. 206: 347-352.

Ouimet, C. C., T. L. McGuinness, and P. Greengard (1984) Immunocytochemical localization of calcium/calmodulin-dependent protein kinase II in rat brain. Proc. Natl. Acad. Sci. USA 81: 5604-5608.

Parker, P. J., L. Coussens, N. Totty, L. Rhee, S. Young, E. Chen, S. Stabel, M. D. Waterfield, and A. Ullrich (1986) The complete primary structure of protein kinase $\mathrm{C}-\mathrm{The}$ major phorbol ester receptor. Science 233: 853-859.

Routtenberg, A. (1985) Protein kinase $\mathrm{C}$ activation leading to protein $F_{1}$ phosphorylation may regulate synaptic plasticity by presynaptic terminal growth. Behav. Neural. Biol. 44: 186-200.

Smith, S. J. (1987) Progress on LTP at hippocampal synapses: A postsynaptic $\mathrm{Ca}^{2+}$ trigger for memory storage? Trends Neurosci. 10: 142144.

Wood, J. G., R. W. Wallace, J. N. Whitaker, and W. Y. Cheung (1980) Immunocytochemical localization of calmodulin and a heat labile calmodulin binding protein $\left(\mathrm{CamBP}_{80}\right)$ in rodent brain. J. Cell Biol. 84: 66-76.

Wood, J. G., P. R. Girard, G. J. Mazzei, and J. F. Kuo (1986) Immunocytochemical localization of protein kinase $C$ in identified neuronal compartments of rat brain. J. Neurosci. 6: 2571-2577.

Worley, P. F., J. M. Baraban, and S. H. Snyder (1986) Heterogeneous localization of protein kinase $\mathrm{C}$ in rat brain: Autoradiographic analysis of phorbol ester receptor binding. J. Neurosci. 6: 199-207.

Yoshida, Y., F. L. Huang, H. Nakabayashi, and K.-P. Huang (1988) Tissue distribution and developmental expression of protein kinase C isozymes. J. Biol. Chem. 263: 9868-9873.

Zwiller, J., M.-O. Revel, and A. N. Malviya (1985) Protein kinase C catalyzes phosphorylation of guanylate cyclase in vitro. J. Biol. Chem. 260: 1350-1353. 